\title{
O tema agrotóxico no contexto escolar: o caso de uma escola pública de Sinop/MT
}

\section{The pesticide theme in the school context: the case of a public school in Sinop/MT}

\author{
Sandra Mara Mezalira (sandmezal@gmail.com) \\ Universidade Federal do Rio Grande do Sul \\ Jeferson Rosa Soares (josoares77@gmail.com) \\ Universida de Federal do Rio Grande do Sul
}

\section{Renan de Almeida Barbosa (renanabh38@gmail.com) Universida de Federal do Rio Grande do Sul}

José Vicente Lima Robaina (joserobaina1326@gmail.com) Universida de Federal do Rio Gra nde do Sul

\begin{abstract}
Resumo: A relação da temática Agrotóxicos com o ambiente escolar e os processos pedagógicos é de grande importância, considerando o ensino e aprendizagem das vantagens e desvantagens do uso desses produtos na agricultura e seu impacto no ambiente e na saúde das pessoas. Os conceitos oriundos dessa temática podem ser desenvolvidos e debatidos com os estudantes de maneira contextualizada e interdisciplinar envolvendo as disciplinas da Biologia, Física e Química que compreendem a área das Ciências da Natureza, além de outras áreas. O presente estudo tem como objetivo verificar as percepções dos estudantes quanto à temática Agrotóxicos em uma escola pública do município de Sinop/MT. A coleta de dados se deu por meio de um questionário com perguntas abertas e fechadas. Foi possível perceber que grande parte dos estudantes possuem conhecimentos prévios sobre a temática, destacando em seus discursos a relação com a palavra "veneno". Pontua-se que a temática não alcança todo o contexto escolar e estudantes, necessitando maior articulação com o cotidiano dos estudantes e a capacitação através da formação dos(as) professores(as).
\end{abstract}

Palavras-chave: Agrotóxicos; Escola Pública; Formação de Professores; Ciências da Natureza.

Resumo traduzido: The relationship of the pesticide theme with the school environment and pedagogical processes is of great importance, considering the teaching and learning of the advantages and disadvantages of the use of these products in agriculture and their impact on the environment and people's health. In this sense, the disciplines of Biology, Physics, and Chemistry from Natural Sciences, as well as other disciplines, can develop and discuss the concepts derived from this theme in a contextualized and interdisciplinary manner. The present study aims to verif y the perceptions of students regarding the topic of pesticides in a public school in Sinop/MT. We used questionnaires with open and multiple-choice questions to collect the data. It was possible to notice that most of the students have previous knowledge on the theme, highlighting in their speeches the relationship with the word poison. The pesticide theme does not reach the entire school and student context, requiring an articulation with the daily lives of students and professional development through the training of teachers.

Palavras-chave traduzidas: Pesticides; Public School; Teachers Training; Natural Sciences.

Recebido em: 30 /04/ 2020

Aceito em: 19/11/2020 


\section{INTRODUÇÃ̃}

Em meio a tantas catástrofes e problemas ambientais provocadas pelo próprio homem devido ao mau uso das tecnologias, à ganância e ao consumo desenfreado, o movimento Ciência, Tecnologia e Sociedade (CTS) surge potencializando o conceito de Alfabetização Científica. Estes conceitos carregam a vontade de transformação de atitudes do dia a dia, em movimentos cientificamente conscientes em busca do Bem Estar Social.

Como afirmam Santos e Mortimer (2002), o objetivo central da educação de CTS: “[...] é desenvolver a alfabetização científica e tecnológica dos cidadãos, auxiliando o aluno a construir conhecimentos, habilidades e valores necessários para tomar decisões responsáveis sobre questões de ciência e tecnologia na sociedade e atuar na solução de tais questões”.

Para tanto, levou-se em conta os seguintes critérios estabelecidos por Ramsey (1993) sobre o que um tema social com enfoque CTS deve obedecer: 1) Se é, de fato, um problema de natureza controvertida, ou seja, se tem opiniões diferentes a seu respeito; 2) Se o tema, em alguma dimensão é social; 3) Se o tema, em alguma dimensão, é relativo a ciência- tecnologia”. As sim, para tal pesquisa, escolheu-se a temática: agrotóxicos. A inquietação se refere a produção e o u so indiscriminado destes produtos, com viés totalmente técnico, levando a diversos embates, como, a influência negativa na questão ambiental e na saúde.

O documentário "O Veneno está na mesa"1 explicita que o Brasil é o país que utiliza princípios ativos de agrotóxicos que circula impunemente e que na maior parte do mundo a muito tempo foram banidos. O Brasil é o campeão mundial em agrotóxicos, utilizados nas lavouras como o soja, milho, trigo, algodão, tomate, causando com o decorrer do tempo várias interferências na saúde atingindo, por exemplo, o sistema nervoso central, lapsos de memória em crianças, redução de imunidade do organismo, desregulação hormonal, entre outros. Além de acometer a saúde humana, também causa vários problemas ambientais como a contaminação das águas, do solo, do ar, desregulando também as cadeias e teias alimentares pela morte de insetos e toda a biodiversidade.

1 “O Veneno está na Mesa” é um documentário com 49 minutos dirigido por Silvio Tendler, a borda sobre como a Agricultura proveniente da Revolução Verde e suas técnicas suplantou a a gricultura tra dicional e vem modificando o ambiente e a vida da população devido as consequências do uso de agrotóxicos. Disponível em: https://www.youtube.com/watch?v=8RVAgD44AGg 
Houve um aumento da produção e o uso dos agrotóxicos nos últimos anos no Brasil e com um índice ainda maior no estado do Mato Grosso (MT), onde a monocultura e o agronegócio são a realidade. O estado é o maior produtor de soja, milho, algodão e gado bovino. Destaca-se, dentre os cinco maiores produtores, o município de Lucas do Rio Verde que produziu em 2010 cerca de 420 mil hectares de soja, milho e algodão e consumiu 5,1 milhões de litros de agrotóxicos nessas lavouras. Os impactos na saúde pública são amplos e envolvem diferentes grupos populacionais, como trabalhadores em diversos ramos de atividades, moradores do entorno de fábricas e fazendas, além de todos nós que consumimos alimentos contaminados, além da água, do solo e do ar também estarem nas mesmas condições (CARNEIRO et al., 2015).

Ao relacionarmos a temática Agrotóxicos ao ambiente escolar e a processos pedagó gicos, este torna-se um tema importante para ser discutido de maneira contextualizada e interdisciplinar. Educadores podem desenvolver junto aos estudantes conceitos que perpassem diferentes disciplinas como Química, Biologia, Física e outras, fazendo com que os estudantes compreendam as vantagens e desvantagens que esses produtos ocasionam na agricultura, no ambiente e na saúde das pessoas. Outras disciplinas como por exemplo História, Geografia, Filosofia e Sociologia podem potencializar o debate escolar sobre a temática, contribuindo para melhor compreensão dos aspectos históricos e das relações entre os seres humanos e com a natureza, na interface do desenvolvimento econômico que determina o sistema de produção, e no caso da agricultura, elucidando a origem, funções e impactos do uso dos agrotóxicos.

Sendo assim, a interdisciplinaridade fundamentada pelos pressupostos CTS e por teorias de aprendizagem valorizam o aluno no processo, potencializando e ampliando o conhecimento e ainda, despertando um senso crítico para que os mesmos possam intervir em suas realidades, no caso desta investigação sobre o tem agrotóxicos.

Neste contexto, a Base Nacional Comum Curricular (BNCC) sendo um documento de caráter normativo e orientador “[...] apresenta os Direitos e Objetivos de Aprendizagem e Desenvolvimento que devem orientar a elaboração de currículos para as diferentes etapas de escolarização" (BRASIL, 2016, p. 24). Quanto à temática ambiental, esta é encontrada de modo superficial na Habilidade EF08CI16, onde explicita-se que "Discutir iniciativas que contribuam para reestabelecer o equilíbrio ambiental a partir da identificação de alterações climáticas regionais e globais provocadas pela intervenção humana" (p.102), demonstrando que as questões ambientais são abordadas de forma incipiente na BNCC, sendo inexistente sua abordagem nas diferentes áreas do conhecimento. Nesse sentido, Almeida e Amaral (2005, p. 01) abordam a 
Edição Especial: XVI Encontro sobre Investigação na Escola - EIE

necessidade de trabalharmos nessa relação, pois é preciso ter um “[...] ponto de partida a escolha de temas representativos da realidade local e da vida social dos alunos".

Já ao relacionar a temática com o Documento de Referência Curricular de Mato Grosso (DCR) das séries finais do Ensino Fundamental não se encontra nada relativo dire tamente ao descritor Agrotóxico. No entanto, realizando a leitura de algumas Unidades Temáticas do $7^{\circ}$ ano, estas sugerem aproximações ao tema, tais como: Unidade Temática: Matéria e Energia e traz a Habilidade (EF07CI06.2MT), elenca que devemos "comparar as relações estabelecidas no mundo do trabalho e estabelecendo diferenças entre aquelas da agricultura de subsistência as da monocultura em larga escala”. Para o $9^{\circ}$ ano - na Unidade Temática: O sujeito e seu lugar no mundo, traz a Habilidade - (EF09GE02) diz: “Analisar a atuação das corporações internacionais e das organizações econômicas mundiais na vida da população em relação ao consumo, à cultu ra e à mobilidade", com um dos Objetos do Conhecimento: “Agronegócio no Mato Grosso e as transformações do espaço geográfico"

Assim, com o objetivo de verificar as percepções dos estudantes quanto a temática agrotóxico, foi realizada uma pesquisa com estudantes do Ensino Fundamental de uma escola estadual do município de Sinop/MG. A coleta de dados se deu por meio de um questionário com questões abertas e fechadas.

É importante ressaltar, que a autora principal deste trabalho é professora efetiva da disciplina de Ciências na escola básica de Sinop no estado do Mato Grosso onde foi ap licado o questionário aos estudantes e que no momento estava em sala de aula neste estado. Além disso, a temática em questão é abordagem principal de seu projeto de doutorado no Programa de PósGraduação Educação em Ciências: Química da Vida e Saúde da Universidade Federal do Rio Grande do Sul (UFRGS).

\section{CONTEXTO E DETALHAMENTO DAS ATIVIDADES}

Esse relato surge das reflexões propostas no grupo de investigação do Cirandar da UFRGS. O coletivo é composto de professores da educação básica, de professore s do ensin o superior e estudantes de graduação e pós-graduação da mesma instituição. O grupo teve seu primeiro encontro presencial em agosto de 2019, com o objetivo de investigar as inquie tações nos mais diversos contextos escolares e não escolares.

Para tanto, busca-se investigar as percepções de estudantes a respeito da temática dos agrotóxicos. Para verificar as percepções, utilizamos como procedimento metodológico a

Recebido em: 30 /04/ 2020

Aceito em: 19/11/2020 
elaboração e a aplicação de um questionário com questões abertas e fechadas com os es tudan tes do ensino fundamental nas turmas de $8^{\circ}$ e $9^{\circ}$ ano de uma escola pública localizada no município de Sinop/MT, com faixa etária de 12 a 15 anos de idade, totalizando 36 estudantes.

O questionário continha dez questões, sendo que destas foram selecionadas três delas como um recorte para esta escrita. As questões foram escolhidas: 1) O que são os agrotóxicos? 2) Para que serve os agrotóxicos? e 3) Qual o meio que ouviram falar sobre os agro tóxicos?

É importante justificar que os sujeitos participantes desta investigação, estão imersos em um contexto dominado pelo agronegócio e pelas suas reais consequências na sociedade. Há extensas terras mecanizadas com plantações, principalmente, de soja, milho e algodão com utilização fortíssima de fertilizantes e agrotóxicos.

Também é preciso considerar, que a maioria dos estudantes participantes da pesquisa, percorrem quilômetros de distância para chegar até a escola, alguns por transporte concedido pelo estado, outros de bicicleta e alguns a pé. Estes estudantes são provenientes de diversos bairros da cidade de Sinop e também do centro urbano. A maioria deles é de classe econômica baixa.

\section{ANÁLISE E DISCUSSÃO DO RELATO}

Com base nas respostas a partir da aplicação do questionário com os estudantes da escola pesquisada, buscou-se apresentar questões para atender à problemática da pesquisa, a qual consistia em analisar as percepções ambientais dos estudantes das referidas turmas da escola em relação aos seus conhecimentos sobre os agrotóxicos no município de Sinop/MT.

Neste sentido, ao serem perguntados sobre o que é agrotóxicos, várias palavras emergem nas respostas dos estudantes tais como: defensivos agrícolas, venenos e produtos. Dessa forma, os dados apresentados elencam um conhecimento prévio sobre o tema proposto e os estudantes conseguem identificar que esses produtos estão presentes em seus contextos. Consideram também que esse tema constitui um grupo de substâncias, com a finalidades de controle de pragas e doenças nas diferentes culturas e plantações. Esses dados estão apresentados na Figura 1 a seguir. 

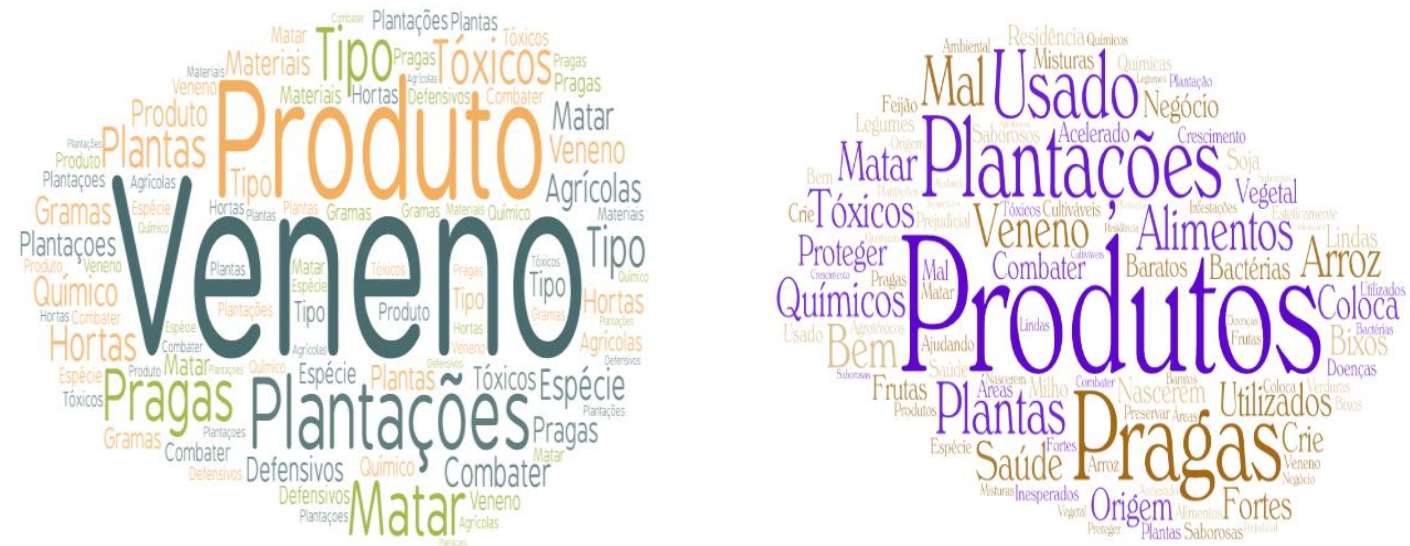

Figura 1: Pa lavras com maiores destaques na visão de estudantes para a pergunta: Oque são agrotóxicos, na ordem, primeiro $8^{\circ}$ a no e na segunda $9^{\circ}$ ano.

Ao serem questionados sobre para que servem os agrotóxicos, o que mais se destaca nos discursos dos estudantes das duas turmas são as palavras: plantações, matar, insetos, pragas, ervas daninhas gramas. Portanto, a maioria dos estudantes destaca que os agrotóxicos são utilizados para matar insetos e pragas que agridem as plantações, em contrapartida nos chama a atenção que $39 \%$ do total de estudantes não sabem para que servem esses produtos, demonstrando que há uma enorme lacuna a ser trabalhada nos espaços escolares e realidades dos mesmos. Esses dados estão apresentados na Figura 2 a seguir.
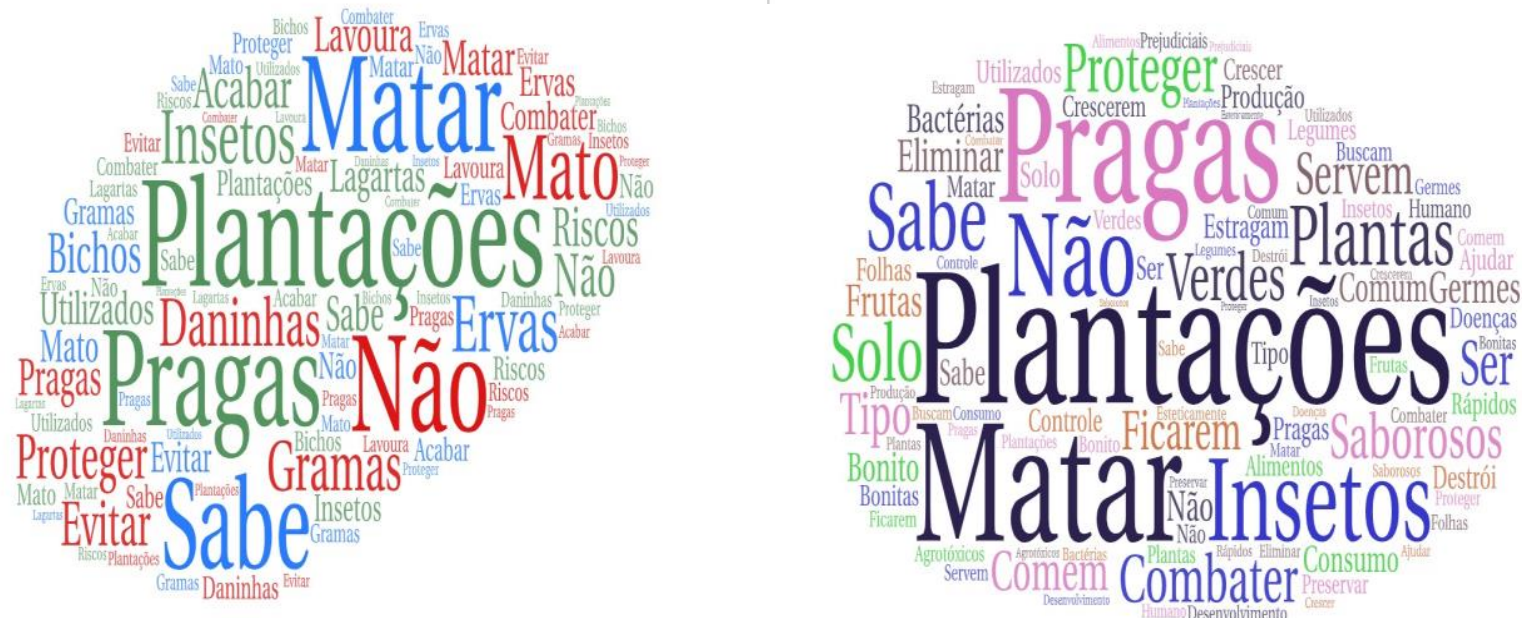

Figura 2: Pa lavras com maiores destaques na visão de estudantes para a pergunta: Pa ra que servem os a grotóxicos, na ordem, primeiro $8^{\circ}$ a no e na segunda $9^{\circ}$ a no. 
Edição Especial: XVI Encontro sobre Investigação na Escola - EIE

ISSN: 2595-4520 Vol. 4, n. 2. 2021

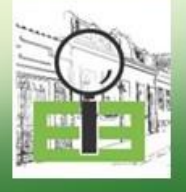

Ao serem perguntados sobre qual meio de comunicação ouviram falar sobre o tema Agrotóxicos, chama a atenção o fato de que nas duas turmas o meio de comunicação co m maior destaque é a TV com $78 \%$ e $89 \%$ das respostas, em seguida a Internet com $61 \%$ das respostas nas duas turmas, o que demonstra que esses são os principais meios que essa temática vem sendo absorvida pelos estudantes. Isso demonstra que a mídia tem um papel importante no olhar construído por esses estudantes sobre o tema. Destaca-se que o material oriundo dessas mídias pode ser utilizado para realizar discussões na promoção de temas relevantes para os estudantes em diferentes contextos. Em contraponto elenca-se que esses meios de comunicação também podem servir pata fins de manipulação e manobras de ideológicas, de divulgação da ciência e tecnologia com interesses próprios de grupos hegemônicos. Além disso, devemos ter em conta o fato de estes meios serem frequentemente utilizados como propagadores de informações falsas.

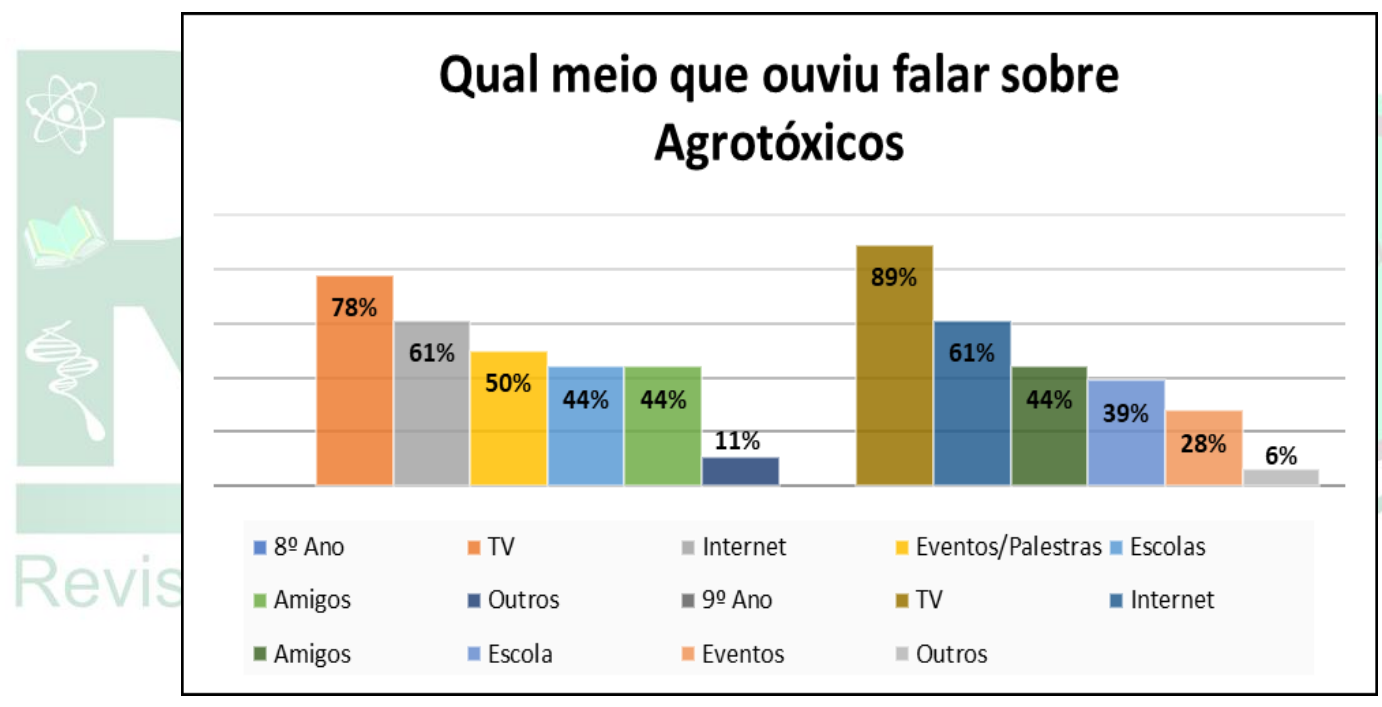

Figura 3: Pa lavras com maiores destaques na visão de estudantes para a pergunta: Por qual meio ou vira m falar sobre o que são a grotóx icos, na ordem, prim eiro $8^{\circ}$ a no e na segunda $9^{\circ}$ a no.

Chama a atenção nas respostas dos estudantes que a escola é a $4^{\mathrm{a}}$ colocad a na questão citada acima, demonstrando que outros espaços têm sido mais importantes na exploração da temática dos agrotóxicos e que nos processos escolares a temática não vem tendo muita importância. Esses dados causam uma preocupação, pois a escola é con siderada um es paço em que deve ser trabalhado problemas de grande impacto nas comunidades. A escola tem como uma de suas funções relacionar o conhecimento escolar diretamente com a realidade de seus estudantes, assim, a temática aqui proposta pode ser trab alhada na escola por meio de diferentes formas tais como: CTS, Educação Ambiental e Interdisciplinaridade, foco de pesquisa dos autores do relato.

Recebido em: 30 /04/ 2020 


\section{CONSIDERAÇÕES FINAIS}

Percebe-se que a maioria dos estudantes possuem um conhecimento prévio sobre o que são agrotóxicos quando destacam "veneno" em seus discursos, mas, no entanto, pontuamos que a temática não alcança a todos e não está sendo articulada ou discutida dentro dos seus contextos e escolas. Isso deve-se em parte a uma lacuna na formação tanto do professor quanto do estudante.

Deve-se levar em consideração que independente da função e para que se utilizam esses produtos, o uso inadequado pode trazer enormes consequências a qualidade de vida dos seres humanos, aos animais e a natureza como um todo.

Quando os estudantes destacam em seus discursos a TV e a Internet como meio de comunicação onde ouviram falar sobre Agrotóxicos, precisamos levar em consideração dois pontos: o primeiro que os veículos de comunicação podem ser meios de se obter conhe cimento, porém pode ser também um meio de alienação, interferindo no modo de como as pessoas veem o mundo.

Portanto destaca-se a importância de um ensino centrado na realidade do estudante, o que fará que o mesmo consiga debater e refletir sobre os problemas apresentados junto a sua realidade e que a partir disso tenham condições de minimizar ou mesmo resolver problemas com base no conhecimento adquirido.

Neste sentido, o que se vê na relação de temáticas ambientais com as políticas educacionais é um caminho oposto e de total distanciamento de políticas públicas e de documentos que embasam a Educação tais como a BNCC e o DRC e por conseguinte os currículos e os espaços escolares. Conclui-se que a escola tem como um de seus objetivos mais importantes formar cidadãos críticos perante o mundo ao qual pertencem e para que isso aconteça os estudantes e professores devem participar de forma coletiva no processo de ensino e aprendizagem em ambiente escolar e fora dele.

\section{REFERÊNCIAS}

ALMEIDA, N. P. G.; AMARAL, E. M. R. Projetos temáticos como alternativa para um ensino contextualizado das ciências. Enseñanza de las Ciencias, número extra, 2005. 
Edição Especial: XVI Encontro sobre Investigação na Escola - EIE

BRASIL. Base Nacional Comum Curricular. Brasília: MEC, 2016. Disponível em: http://basenacionalcomum.mec.gov.br/documentos/bncc2versao.revista.pdf. Acesso em: 21 nov. 2019.

CARNEIRO, F. F. et al. (Org.). Dossiê ABRASCO: um alerta sobre os impactos dos agrotóxicos na saúde. Rio de Janeiro: EPSJV; São Paulo: Expressão Popular, 2015.

MATO GROSSO. Documento de Referência Curricular para Mato Grosso - Anos Finais. Disponível em:http://cos.seduc.mt.gov.br/upload/permanente/Arquivo/Anos\%20Finais_Documento \%20de\%20Refer\%C3\%AAncia\%20Curricular\%20para\% 20Mato\%20Grosso 2270787 45843.pdf. Acesso em: 20 nov. 2018.

RAMSEY, J. The science education reform movement: implications for social responsibility, 1993. Disponível em: https://onlinelibrary.wiley.com/doi/abs/10.1002/sce.3730770210. Acesso em: 21 nov. 2019.

SANTOS, W. P.; MORTIMER, E. F. Uma Análise de Pressupostos Teóricos da Aborda gem C-TS (Ciência - Tecnologia - Sociedade) no Contex to da Educação Brasileira. Ensaio - Pesquisa em Educação em Ciências, Belo Horizonte, v. 2, n. 2, dez. 2002. 